\title{
PATTERN AND OUTCOME OF NEONATAL ADMISSIONS- AN EXPERIENCE FROM A DISTRICT LEVEL SCNU
}

\author{
Rattan Singh Manhas ${ }^{1}$, Ashu Jamwal2, Sunil Dutt Sharma³, Ghanshyam Saini ${ }^{4}$, Pallavi Sharma 5 , Tarundeep Kour 6
}

${ }_{1}^{1}$ Senior Consultant, Department of Paediatrics, J and K Health Services, Jammu, Jammu and Kashmir, India.

${ }^{2}$ Associate Professor, Department of Paediatrics, GMC, Jammu, Jammu and Kashmir, India.

${ }^{3}$ Associate Professor, Department of Paediatrics, GMC, Jammu, Jammu and Kashmir, India.

4 Professor, Department of Paediatrics, GMC, Jammu, Jammu and Kashmir, India.

${ }^{5}$ Registrar, Department of Paediatrics, GMC, Jammu, Jammu and Kashmir, India.

${ }^{6}$ Dental Officer, DEIC Paediatrics, GMC, Jammu, Jammu and Kashmir, India.

\section{BACKGROUND}

ABSTRACT

Neonatal mortality still continues to be a significant contributor to the infant mortality rate in India. Also the rural-urban gap in the neonatal mortality rate is significant. It is imperative therefore to shift the focus of neonatal research to the peripheral health facilities and understand the challenges posed by the socio-demographic profile of the populations in these areas.

Aim: To study the pattern of neonatal admissions and record their outcomes in a district level SCNU of Doda District.

\section{MATERIALS AND METHODS}

A retrospective descriptive study, which analyses the data recorded in SCNU, Doda District Hospital, from 01/04/2016 to $31 / 03 / 2017$.

\section{RESULTS}

A total of 538 inborn babies and 71 outborn babies were admitted to SCNU during this one year period. 76.62\% of the inborn babies had a birth weight of more than 2500 gms, while $23.38 \%$ had low birth weight. $63.38 \%$ of the outborn babies had a birth weight more than 2500 gms, while $36.62 \%$ had a low birth weight. Of the inborn and outborn babies, $4.23 \%$ and $2.97 \%$ were very low birth weight and $2.82 \%$ and $0.19 \%$ were extremely low birth weight respectively. Jaundice, sepsis and respiratory distress and birth asphyxia were the major morbidities with which babies were admitted to the SCNU. 59\% of the outborns and 56\% of the inborn babies were discharged successfully, while $31 \%$ of the total admissions required referral. $11 \%$ and $7 \%$ of the outborn and inborn babies left against medical advice, whereas $3 \%$ and $2 \%$ respectively died.

\section{CONCLUSION}

Data analysis from sick newborn care of the district hospitals can provide valuable insight into the problems faced by specific units, taking into consideration the terrain and the demographic profile. Further research for facilitating newborn care in these areas is the need of the hour.

\section{KEY WORDS}

Neonatal Morbidity, Neonatal Mortality, Special Care New Born Unit.

HOW TO CITE THIS ARTICLE: Manhas RS, Jamwal A, Sharma SD, et al. Pattern and outcome of neonatal admissions- an experience from a district level SCNU. J. Evolution Med. Dent. Sci. 2018;7(45):4844-4846, DOI: 10.14260/jemds/2018/1079

\section{BACKGROUND}

High neonatal mortality still continues to be a significant contributor to the infant mortality rate in India. At a national level, neonatal deaths accounted for $67.8 \%$ of the total infant deaths in 2015. The data clearly show that rural-urban gap in the neonatal mortality rate is significant, whereas the overall neonatal mortality rate is 25 , it ranges from 15 in urban areas to 29 in rural areas.(1)

Research shows that about $62 \%$ of the total neonatal deaths occurred during the first 3 days of life. The first day alone accounted for two- thirds.

'Financial or Other Competing Interest': None.

Submission 06-09-2018, Peer Review 18-10-2018,

Acceptance 25-10-2018, Published 05-11-2018.

Corresponding Author:

Dr. Ashu Jamwal,

Ram Niwas, 356-A, Gandhinagar,

Jammu-180004,

Jammu and Kashmir, India.

E-mail: ashu.sainik@gmail.com

DOI: $10.14260 /$ jemds $/ 2018 / 1079$

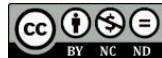

Most of asphyxia, prematurity and malformation related mortality and one-half of sepsis related deaths occurred in the first week of life.(2) Also it has been seen that delay in identification of danger signs, delayed decision to seek care and absence of health personnel during transport and referral had significant correlation with mortality.(3,4)

In order to further bring down the neonatal and infant mortality and to bridge the urban rural gap it is imperative to shift the focus of neonatal research to the peripheral level health facilities and understand the challenges posed by the socio-demographic profile of the populations in these areas.

Doda is a district in the eastern part of Jammu division of the Indian state of Jammu and Kashmir. It has twelve tehsils and 406 villages. Lying in the middle and outer Himalayan ranges, the district has a very rigged and mountainous terrain. Doda area can also be called as a land of lofty mountains, deep gorges, valleys and meadows showing great variation in elevation. Many areas are covered with snow during winter season.(5)

According to the 2011 census, Doda district has a population of 409,936 and a population density of 46 inhabitants per square kilometre. Doda has a sex ratio of 922 
females for every 1000 males and a literacy rate of $65.97 \%$. Its population growth rate over the decade 2001 - 2011 was $27.89 \% .6)$

Its vastness and hilly terrain and the rural population living in far-flung areas is huge, makes the newborn care in the region especially challenging.

\section{Objectives}

The District hospital Doda had newborn care facility, SCNU, commissioned in the hospital in March 2013 under National Health Mission. The present study aims to analyse the pattern of neonatal admissions and record their outcomes in a district level SCNU of Doda District.

\section{MATERIALS AND METHODS}

The recorded data from the labour room, operation theatres, and special newborn care unit of District Hospital, Doda, from April 2016 to March 2017 was retrieved. This was as per the reporting format for the Newborn facility. The available data was analysed.

\section{RESULTS}

- $\quad$ During the period, a total of 3036 deliveries were conducted in the hospital including 873 caesarean sections. No. of live births were 2986, while still births were 84

- A total of 538 inborn babies and 71 outborn babies were admitted to SCNU during this one year period.

- Out of the inborn babies 352 (65.4\%) were males and $186(34.6 \%)$ were females, while of the outborn babies $48(67.6 \%)$ were males and $23(32.39 \%)$ were females (Table 1).

\begin{tabular}{|c|c|c|c|}
\hline Sl. No. & Total Number & Inborn & Outborn \\
\hline 1 & Admissions in unit & 538 & 71 \\
\hline 2 & Male & 352 & 48 \\
\hline 3 & Female & 186 & 23 \\
\hline \multicolumn{3}{|c|}{ Table 1 } \\
\hline
\end{tabular}

\section{Birth Weight}

- Out of the inborn babies $76.62 \%$ had a birth weight of more than 2500 gms, while $23.38 \%$ had low birth weight.

- $\quad 63.38 \%$ of the outborn babies had a birth weight more than 2500 gms, while $36.62 \%$ had a low birth weight.

- Of the inborn and outborn babies, $4.23 \%$ and $2.97 \%$ were very low birth weight and $2.82 \%$ and $0.19 \%$ were extremely low birth weight respectively.

\section{Morbidity Profile}

Out of the total admitted babies, 242 inborns and 33 outborns did not have any significant ailment other than some being low birth weight and were admitted for observation only. The morbidity profile among the remaining has been depicted in Table 2.

\begin{tabular}{|c|c|c|}
\hline Morbidity Profile & Inborn & Outborn \\
\hline Jaundice requiring phototherapy & $33.1 \%$ & $36.8 \%$ \\
\hline Respiratory distress syndrome & $10 \%$ & $5.2 \%$ \\
\hline Sepsis/ Pneumonia/ Meningitis & $12.6 \%$ & $31.5 \%$ \\
\hline Meconium Aspiration Syndrome & $5.7 \%$ & $5.2 \%$ \\
\hline Birth asphyxia/ HIE & $2.6 \%$ & $2.6 \%$ \\
\hline
\end{tabular}

\begin{tabular}{|c|c|c|}
\hline Hypothermia & $29 \%$ & $10.5 \%$ \\
\hline Hypoglycaemia & $1.35 \%$ & $7.8 \%$ \\
\hline \multicolumn{2}{|c|}{ Table 2 } \\
\hline
\end{tabular}

\begin{tabular}{|c|c|c|c|c|}
\hline $\begin{array}{c}\text { Management (No. of } \\
\text { Babies) Received }\end{array}$ & $\begin{array}{c}\text { Inborn } \\
\text { No. }\end{array}$ & $\begin{array}{c}\text { Outborn } \\
\text { No. }\end{array}$ & $\begin{array}{c}\text { Inborn } \\
\mathbf{\%}\end{array}$ & $\begin{array}{c}\text { Outborn } \\
\mathbf{\%}\end{array}$ \\
\hline Phototherapy & 60 & 8 & $11.47 \%$ & $11.27 \%$ \\
\hline Antibiotics & 461 & 62 & $88.15 \%$ & $87.32 \%$ \\
\hline Oxygen & 2 & 1 & $0.38 \%$ & $1.41 \%$ \\
\hline \multicolumn{5}{|c|}{ Table 3 } \\
\hline \multicolumn{5}{|c|}{}
\end{tabular}

\section{Outcome}

$59 \%$ of the outborns and $56 \%$ of the inborn babies were discharged successfully, while $31 \%$ of the total admissions required referral. $11 \%$ and $7 \%$ of the outborn and inborn babies left against medical advice, whereas $3 \%$ and $2 \%$ respectively died.

\section{DISCUSSION}

Our study shows that jaundice, sepsis and respiratory distress and birth asphyxia were the major morbidities with which babies were admitted to the SCNU. Hypothermia was a finding in 86 inborn and 4 outborn babies. Also 31\% of both inborn and outborn babies required referral, while $11 \%$ and $7 \%$ left against medical advice. The outcome of these babies is not known, as the nearest tertiary level health care facility is 200 kilometres away.

Baruah et al in their study of morbidity and mortality profile of newborns admitted in SCNU of a teaching hospital of Assam also reported sepsis, jaundice and birth asphyxia as the common morbidities. They reported that $42 \%$ of the babies were low birth weight, whereas in our study $36.62 \%$ of the inborn and $23.38 \%$ of the out born babies were low birth weight. (7)

Malik S et al in a study from NICU of a teaching hospital of Bhopal reported $63.5 \%$ babies as low birth weight and $44.55 \%$ as preterm. The high incidence of low birth weight and preterm was because it was a tertiary care NICU and acted as a referral centre for high risk babies from neighbouring districts. Respiratory distress (47.2\%), neonatal sepsis (45.1\%), HIE ( $43.94 \%$ ), neonatal convulsions $(12.5 \%)$ and hyperbilirubinaemia $(24.1 \%)$ were the top five neonatal morbidities in their study. ${ }^{(8)}$ Rasania et al in a study from a rural tertiary care hospital of Gujrat reported that late preterms are at higher risk of morbidities like sepsis, hyperbilirubinaemia, RDS and hypoglycaemia and require special care. ${ }^{(9)}$

India is one of the largest contributors in the pool of neonatal deaths in the world. Aggarwal KC et al studied the predictors of mortality in newborns referred to a tertiary hospital and concluded that 435 of the deaths took place in the first 24 hours. Severe hypothermia, severe respiratory distress, admissions within first 24 hours of life, absence of health personnel during transport and referral from any hospital had significant correlation with mortality. Asphyxia and low birth weight were the main causes of death in the early neonatal period, whereas sepsis had maximum contribution in deaths during late neonatal period.(3)

Rai SK et al studied the causes of and contributors to infant mortality in a rural community of North India and concluded that neonatal deaths contributed to 54.35 of infant deaths and $39 \%$ occurred on the first day. Birth asphyxia (31.5\%) followed by low birth weight/ prematurity $(26.5 \%)$ 
were the most common causes of neonatal deaths. Care seeking was delayed among $50 \%$ of neonatal deaths. Deaths due to LBW/ prematurity were mostly due to delay in identification of danger signs and decision making to seek care.(4)

About 0.75 million neonates die in India every year, the highest for any country in the world. The rate of decline in NMR and to some extent EMNR has accelerated with the introduction of National Rural Health Mission in mid 2005. But there is still a huge disparity between and even within the states. There is an interplay of different demographic, educational, socioeconomic, biological and care seeking factors which are responsible for the differentials and the high burden of neonatal mortality. Addressing in equity in India is an important cross-cutting action that will reduce newborn mortality.(10)

\section{CONCLUSION}

- The morbidity profile of district level SCNUs differs considerably from the tertiary level referral centres.

- $\quad$ Some problems are area specific like Doda being a hilly area with cold climate. Hypothermia was a significant finding in the newborns.

- Health care programmes should be directed towards addressing the risk factors in the community as well as improving health care delivery at district level, so that referrals can be minimised.

- Further research focussed on difficulties encountered in newborn care in hilly and difficult terrain is the need of the hour in order to ensure intact survival of the newborns and further bring down the neonatal mortality.

\section{REFERENCES}

[1] Millennium Development Goals: final country report of India, 2017. Ministry of Statistics and Programme Implementation, 27/11/2017.
[2] Sankar MJ, Natrajan CK, Das RR, et al. When do newborns die? A systematic review of timing of overall and cause-specific neonatal deaths in developing countries. J Perinatol 2016;36(Suppl 1):S1-S11.

[3] Aggarwal KC, Gupta R, Sharma S, et al. Mortality in new-borns referred to tertiary hospital: an introspection. J Family Med Prim Care 2015;4(3):4358.

[4] Rai SK, Kant S, Srivastava R, et al. Causes of and contributors to infant mortality in a rural community of North India: evidence from verbal and social autopsy. BMJ Open 2017;7(8):e012856.

[5] Tehsils in Doda district, Jammu and Kashmir -Census 2011.

[6] District Census Handbook: Doda, Directorate of Census Operations, Jammu \& Kashmir, 2017.

[7] Baruah MN, Panyang PP. Morbidity and mortality profile of new-borns admitted to the Special Care New-born Unit (SCNU) of teaching hospital of upper Assam, India - a three year study. Journal of Medical Science and Clinical Research 2016;4(8).

[8] Malik S, Gohiya P, Khan IA. Morbidity profile and mortality of neonates admitted in Neonatal Intensive Care Unit of a Central India Teaching institute: a prospective observational study. J Clin Neonatol 2016;5(3):168-73.

[9] Rasania M, Muley P. Morbidity profile and immediate outcome of late preterm neonates compared to term neonates in a rural tertiary care hospital of Gujrat. Int J Contemp Pediatr 2017;4(4):1329-33.

[10] Sankar MJ, Neogi SB, Sharma J, et al. State of new-born health in India. J Perinat 2016;36(Suppl 3):S3-S8. 